\title{
Boiling of a refrigerant of low GWP on the surface with copper microchannels
}

\author{
Robert Kaniowski ${ }^{1, *}$, and Robert Pastuszko ${ }^{1}$ \\ ${ }^{1}$ Kielce University of Technology, Faculty of Mechatronics and Mechanical Engineering, al. 1000-lecia Państwa Polskiego 7 , \\ PL-25-314 Kielce, Poland
}

\begin{abstract}
The boiling curves and heat transfer coefficients between the heating surface and fluid were investigated in the paper. Copper samples with horizontal microchannels of rectangular cross-section, variable depth and width were the objects of the study. The following geometrical parameters have been used: microchannel width $0.2 ; 0.3$ and $0.4 \mathrm{~mm}$, depth between 0.2 and $0.5 \mathrm{~mm}$ (change every $0.1 \mathrm{~mm}$ ). Boiling refrigerant was Novec-649 $(\mathrm{GWP}=1)$, and the experiment was performed at atmospheric pressure. Geometrical parameters impact, within a given range of heat flux $3-130 \mathrm{~kW} / \mathrm{m}^{2}$, on the heat transfer process was determined.
\end{abstract}

\section{Introduction}

Digital systems, nuclear reactors, engines, gas turbines are devices generating significant heat fluxes. Miniaturization and increase of power of electronic systems necessitate searching for compact cooling units of high efficiency.

Great demand for effective heat dissipation, mostly from microelectronic chips, determines development of small heat exchangers with the phase change. Passive method is one of the most effective forms of thermal energy transfer with simultaneous maintenance of relatively fixed temperature of the heating surface. Designers of heat exchangers strive to reduce their volume and weight.

In available publications, there are no analytical dependencies which would allow for determining heat transfer coefficient (HTC) at pool boiling for various geometries of structural surfaces. The available correlations concern mostly smooth flat or cylindrical surfaces.

Jaikomar and Kandlikar [1] performed studies on the heat transfer on samples of copper surface in form of open microchannels with porous fin tops (channel widths: $300-762 \mu \mathrm{m}$, depths: $200-400 \mu \mathrm{m}$ ) at atmospheric pressure using $\mathrm{FC}-87$ as boiling fluid. The highest HTC of $20 \mathrm{~kW} / \mathrm{m}^{2} \mathrm{~K}$ was obtained for the channel with the width and depth of $400 \mu \mathrm{m}$. Gheitaghy et al. [2] analysed copper surfaces with microchannels inclined at $45^{\circ}$ in relation to horizontal plane, where the microchannels' parameters were as follows: widths: 0.5-0.7 mm, depths: $0.5-1 \mathrm{~mm}$. The experiment was performed using water as working fluid. The highest HTC (about $120 \mathrm{~kW} / \mathrm{m}^{2} \mathrm{~K}$ ) was obtained for the channel width of $0.5 \mathrm{~mm}$ and depth of $1.4 \mathrm{~mm}$. In turn, Walunj and Sathyabhama [3] investigated rectangular, parabolic and stepped microchannels fabricated on the $10 \mathrm{~mm}$ diameter copper rod with channel widths: $250-800 \mu \mathrm{m}$, height of $500 \mu \mathrm{m}$. They also used water as the working fluid. At the heat flux of $100 \mathrm{~kW} / \mathrm{m}^{2}$, the HTC increased by $21-35 \%$. In the paper [4], the subject of the study was pool boiling of Novec-7300 fluid and self-rewetting water-heptanol mixtures on bare copper surface and a copper surface coated with copper-plated nanofibers. Authors have found that the heat transfer coefficients were greater for surfaces with cooper-plated nanofibre.

Studies on pool boiling heat transfer with water, ethanol, FC-72 and Novec-649 from tunnel structures, microfins, microchannels, microcavities [5-8] and boiling heat transfer with FC-72 flowing in narrow channels [9-11] have been conducted at the Kielce University of Technology for more a decade.

Due to unfavourable impact of traditional refrigerants and working fluids on the climate, it is necessary to replace these fluids of high global warming potential (GWP), such as HFCs (hydrofluorocarbons) and PFCs (perfluorocarbons) with more environmentally friendly alternatives, for instance a new class of fluoroketone fluids, including Novec 649. These fluids were being explored for their use in direct and indirect heat transfer systems and ORC (Organic Rankine Cycle) systems.

The objectives of the present paper are to determine the effect of microchannel width on the HTC for Novec649 boiling.

\section{Experimental setup}

Heat transfer measurements were performed using the experimental stand presented in Fig. 1 and Fig. 2 [5-8]. The main module allows for measuring the temperature difference between fluid and the heating surface

Corresponding author: kaniowski@tu.kielce.pl 


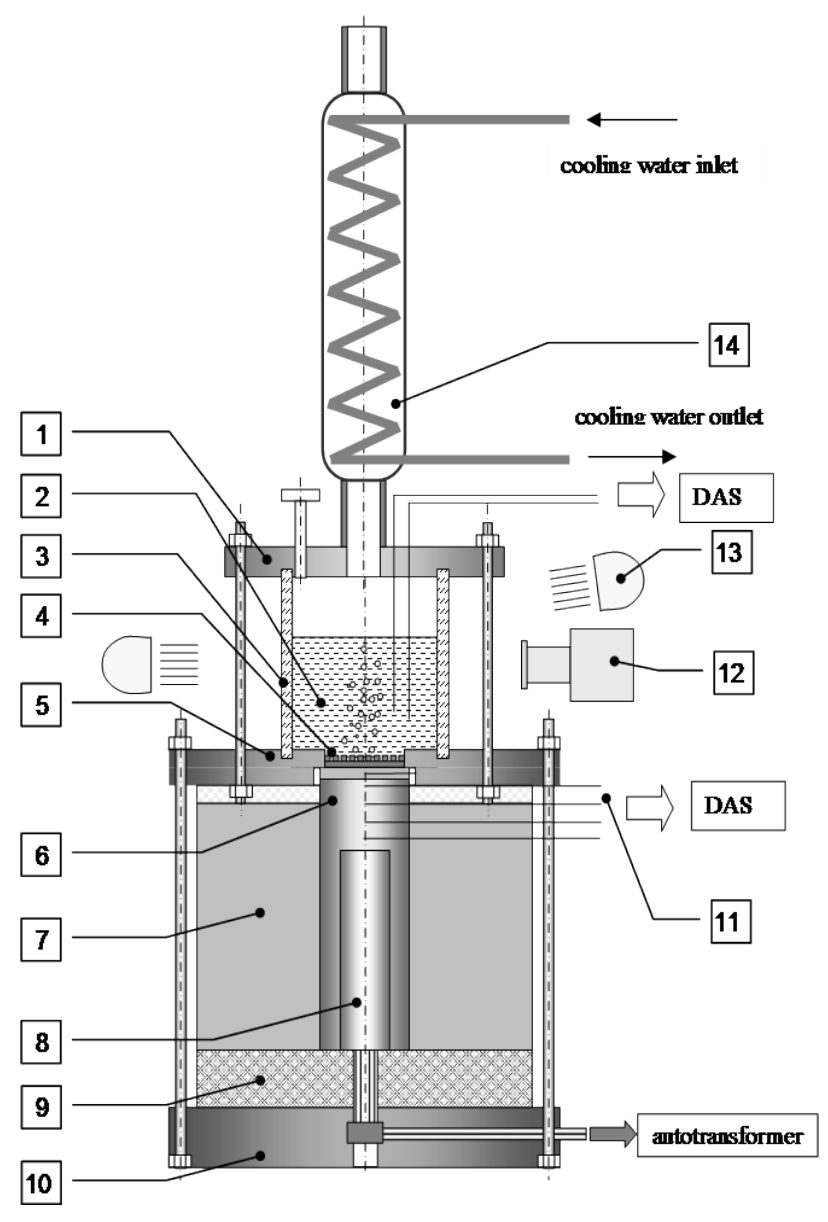

Fig. 1. Main module; 1 - top flange, 2 - boiling liquid, 3 glass vessel, 4 - sample, 5 - Teflon annular flange, 6 - copper bar, 7 - insulation, 8 - cartridge heater, 9 - bottom insulation, 10 - retaining flange, 11 - thermocouples, 12 - digital camera, 13 - lights, 14 - condenser, DAS - Data Acquisition System.

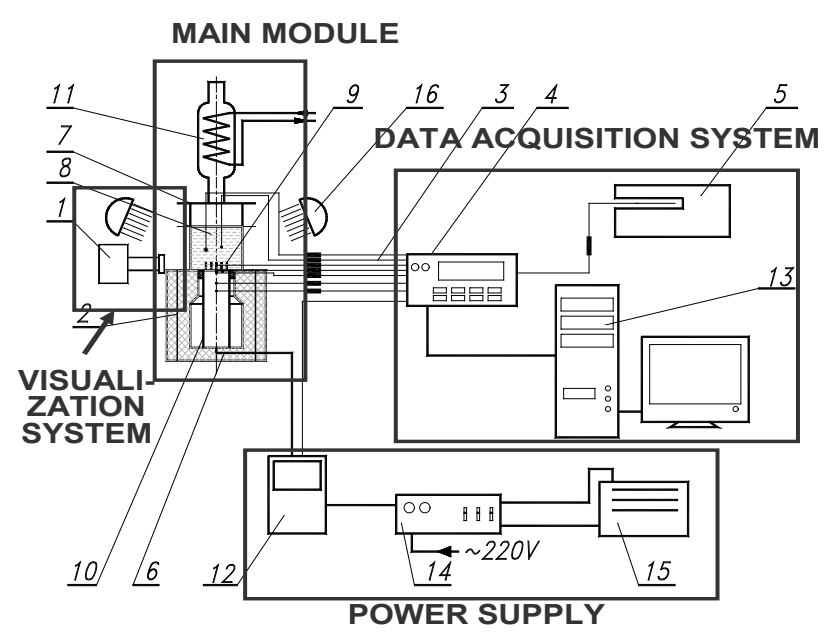

Fig. 2. Pool boiling measurement stand 1 - digital camera, $2-$ Teflon casing, 3 - compensating leads, 4 - data logger, 5 - drywell calibrator, 6 - insulation, 7 - glass vessel, 8 - boiling liquid, 9 - investigated sample, 10 - copper bar with cartridge heater, 11 - condenser, 12 - wattmeter, 13 - PC, 14 - power supply and fuses, 15 - autotransformer, 16 - lights. a)

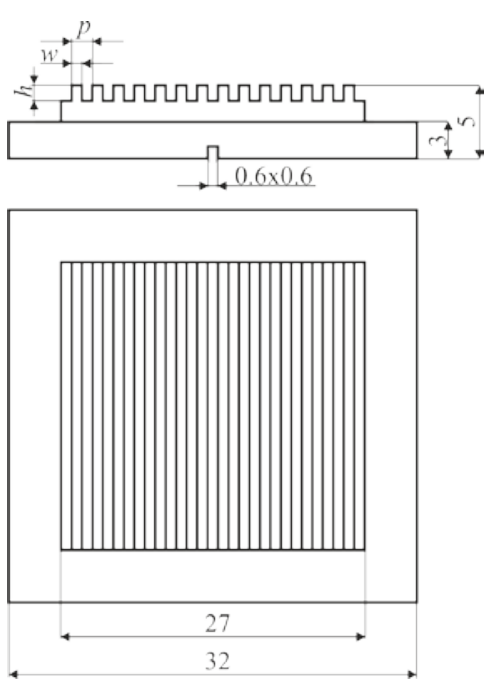

b)

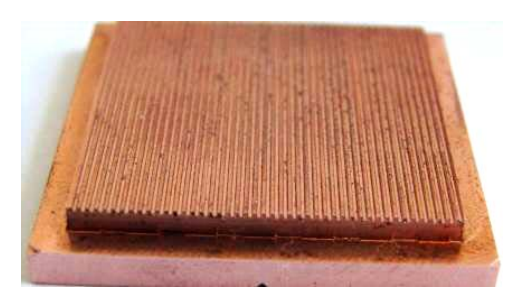

c)

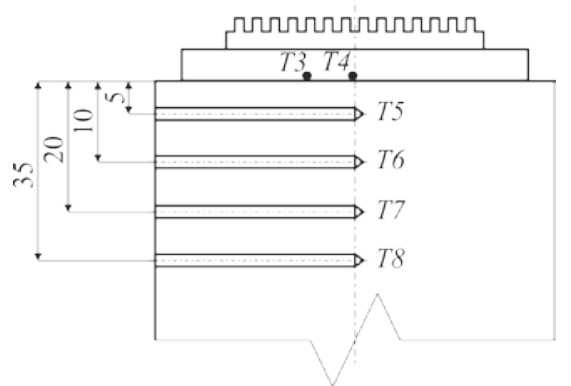

Fig. 3. a) dimension symbols $\mathrm{MC}, \mathrm{b}$ ) view of the specimen $\mathrm{MC}, \mathrm{c}$ ) arrangement of thermocouples.

(superheating) and determining the heat flux. These parameters are necessary to determine the boiling curves.

The cylinder diameter corresponds to the diagonal of the sample base. A $1000 \mathrm{~W}$ electric cartridge heater, 16 $\mathrm{mm}$ in diameter and $100 \mathrm{~mm}$ in length, was installed inside the heating bar.

The estimated uncertainties were as follows: low heat flux $\left(2 \mathrm{~kW} / \mathrm{m}^{2}\right)$ : heat flux $\pm 35 \%$, heat transfer coefficient $\pm 40 \%$, high heat flux $\left(120 \mathrm{~kW} / \mathrm{m}^{2}\right)$ : heat flux $\pm 28 \%$, heat transfer coefficient $\pm 32 \%$.

Measurement of temperature has been performed using $K$ type thermocouples (NiCr-NiAl) of diameter $0.5 \mathrm{~mm}$; their arrangement is presented in Fig. $3 \mathrm{c}$. FLUKE Hydra series II data acquisition system was applied. In order to fix the sample on the heating cylinder, a layer of tin of thickness $\delta_{S n}=0.1 \mathrm{~mm}$ and thermal conductivity $\lambda_{S n}=66.5 \mathrm{~W} /(\mathrm{mK})$ was used. Dimensions and photo of the sample are presented in 
Fig. 3a, b, respectively. Linearity of temperature profile read from the thermocouples $T 3, T 4, T 5, T 6, T 7$ and $T 8$, Fig. 4, was checked, where the determination coefficient $\mathrm{R}^{2}$ reached the value above 0.99 . This proved correctness of the assumption concerning one-dimensional heat transfer in the top section of the heating cylinder.

The specimens with test surfaces were made of copper and had parallel grooves with a constant pitch, made with an end mill of $0.2-0.4 \mathrm{~mm}$ in diameter (CNC machining process). The test section consisted of a 32 x $32 \mathrm{~mm}^{2}$ square copper specimen with a $27 \times 27 \mathrm{~mm}^{2}$ boiling region. The mean roughness of the microchannel surface was $0.15 \mu \mathrm{m}$. Table 1 compiles the surface codes and specifications according to Fig. 3a.

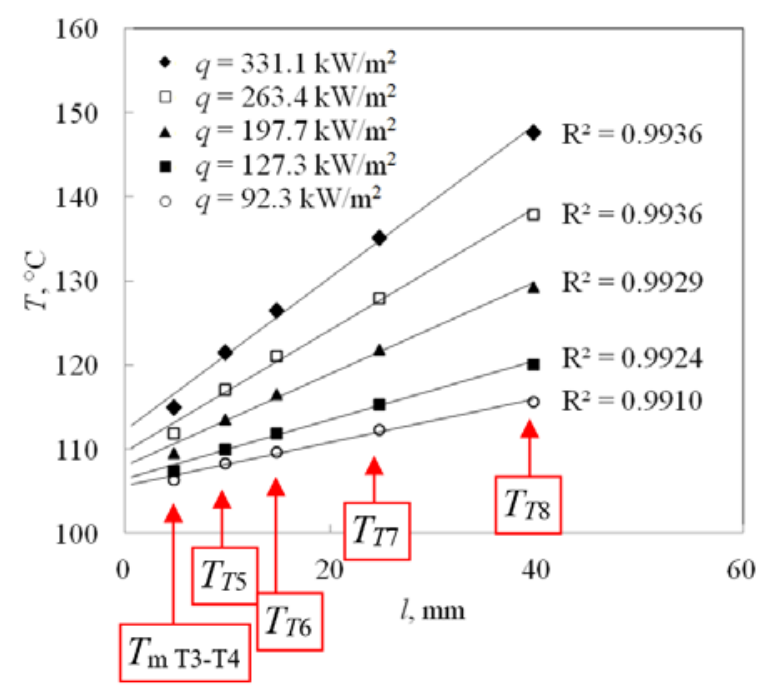

Fig. 4. Temperature vs. thermocouple location in the heating bar, water.

Table 1. MC surface codes and specifications.

\begin{tabular}{lccc}
\hline Sample code & $\begin{array}{l}w \\
\mathrm{~mm}\end{array}$ & $\begin{array}{l}h \\
\mathrm{~mm}\end{array}$ & $\begin{array}{l}p \\
\mathrm{~mm}\end{array}$ \\
\hline MC-0.2-0.4-0.4 & 0.2 & 0.4 & 0.4 \\
MC-0.2-0.3-0.4 & 0.2 & 0.3 & 0.4 \\
MC-0.2-0.2-0.4 & 0.2 & 0.2 & 0.4 \\
\hline MC-0.3-0.5-0.6 & 0.3 & 0.5 & 0.6 \\
MC-0.3-0.4-0.6 & 0.3 & 0.4 & 0.6 \\
MC-0.3-0.3-0.6 & 0.3 & 0.3 & 0.6 \\
MC-0.3-0.2-0.6 & 0.3 & 0.2 & 0.6 \\
\hline MC-0.4-0.5-0.8 & 0.4 & 0.5 & 0.8 \\
MC-0.4-0.4-0.8 & 0.4 & 0.4 & 0.8 \\
MC-0.4-0.3-0.8 & 0.4 & 0.3 & 0.8 \\
MC-0.4-0.2-0.8 & 0.4 & 0.2 & 0.8 \\
\hline
\end{tabular}

With the assumption that the heat transfer is onedimensional, the heat flux was calculated on the basis of the temperature gradient in the copper bar from:

$$
q=\frac{\lambda_{C u}\left(T_{T 8}-T_{T 5}\right)}{l_{T 5-T 8}},
$$

where: $l_{T 5-T 8}=30 \mathrm{~mm}$ is the distance between thermocouples $T 5$ and $T 8$.

The heat transfer coefficient is expressed as:

$$
\alpha=\frac{q}{\Delta T}
$$

The difference between temperatures of the heated surface and liquid $\Delta T$ (superheat) is shown by the following equation, according to Fig. 3:

$$
\Delta T=\frac{T_{T 3}+T_{T 4}}{2}-\frac{T_{T 1}+T_{T 2}}{2}-q\left(\frac{\delta_{s}}{\lambda_{C u}}+\frac{\delta_{S n}}{\lambda_{S n}}\right),
$$

where $\delta_{s}$ is distance between microchannel bottom (base) and thermocouples $T 3$ and $T 4$.

\section{Results}

Before the actual measurements, the fluid was degassed on the experimental stand for about 15 minutes by boiling it. The measurement data was recorded after stabilization of all temperature values within the cooper bar. Further measurements were performed at increasing heat flux until the beginning of the boiling crisis was observed.

Figures 5 and 6 show the dependence of the heat transfer coefficient on the heat flux, at the growing heat flux on MC surfaces for boiling liquid Novec-649. In case of the investigated samples with microchannels, significant intensification of heat transfer was noticed comparing to smooth surface, however the heat transfer coefficient depends on the height and width of the microchannel. Among the investigated samples, the greatest HTC within the range of heat flux $3-90 \mathrm{~kW} / \mathrm{m}^{2}$ was obtained for the sample MC-0.2-0.4-0.4 where the heat transfer coefficient was $\alpha=8.5 \mathrm{~W} / \mathrm{m}^{2} \mathrm{~K}$, for the top limit of the given range of heat flux.

\section{Conclusion}

The analysis of the graphs shows the following conclusions:

1) Comparison of boiling curves of Novec-649 shows the impact of height and width of the microchannel on the heat transfer coefficient.

2) Analyzed surfaces with microchannels allow to obtain heat transfer coefficients within the range of $4.5-$ $9 \mathrm{~kW} / \mathrm{m}^{2}$, which in relation to the flat surface gives a $2-$ 4-fold increase in HTC.

3) The greatest HTC in the range of $3-90 \mathrm{~kW} / \mathrm{m}^{2}$ can be obtained using microchannels of width $0.2 \mathrm{~mm}$ and depth $0.3-0.4 \mathrm{~mm}$. The small width is associated with a small pitch of microchannels, which in turn makes it possible to obtain the largest number of microchannels on the width of the sample.

4) Surfaces with the widest channels $(0.4 \mathrm{~mm})$ allow for obtaining low superheating - initiation of boiling takes place at superheating of $1-1.5 \mathrm{~K}$, which results in great HTC value at small heat fluxes.

5) The main reason for the increase in the heat transfer coefficient when increasing the heat flux was the growing number of active nucleation sites at the bottom of microchannels and its side surfaces. 

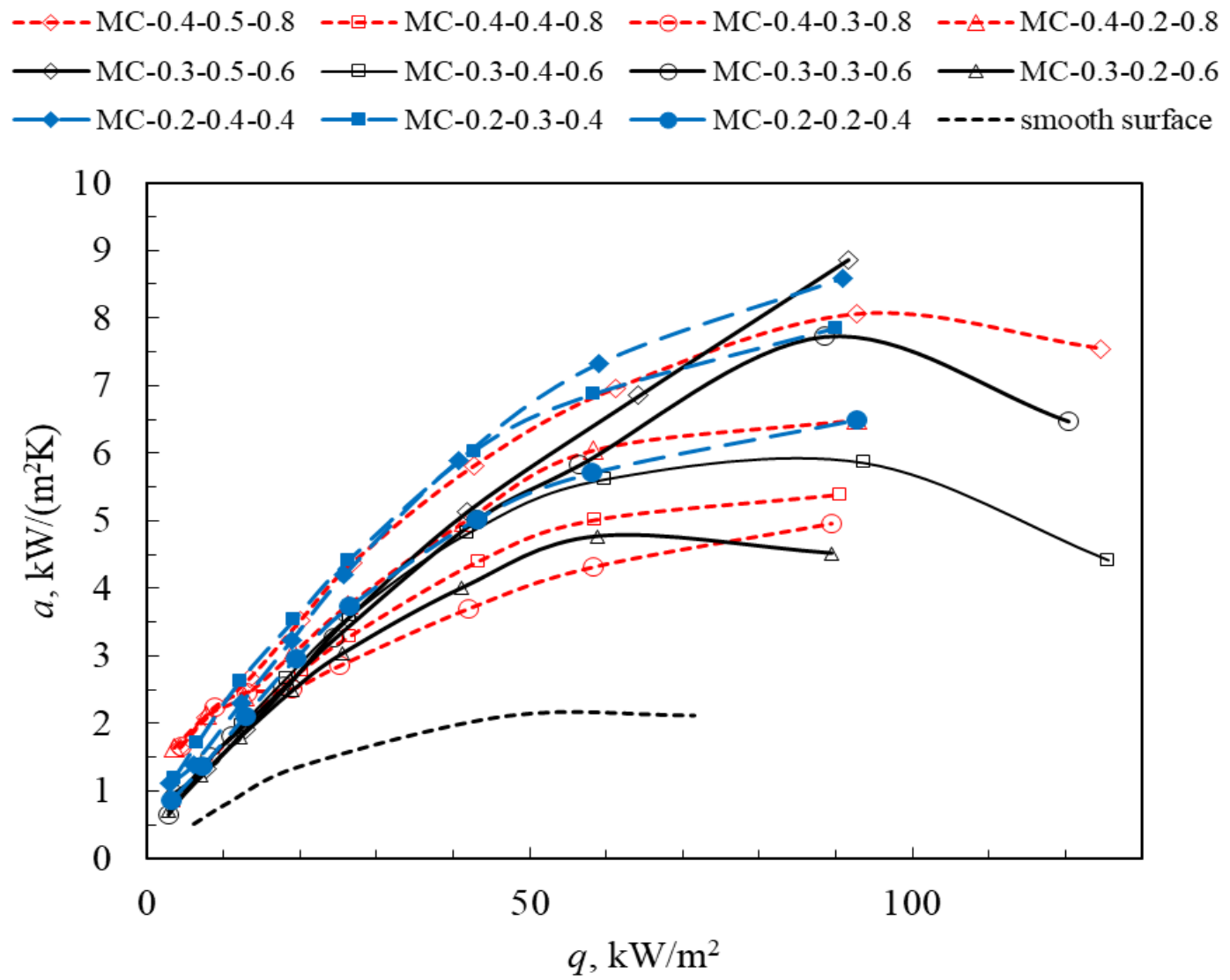

Fig. 5. Boiling curves for Novec-649, heat transfer coefficient vs. heat flux.
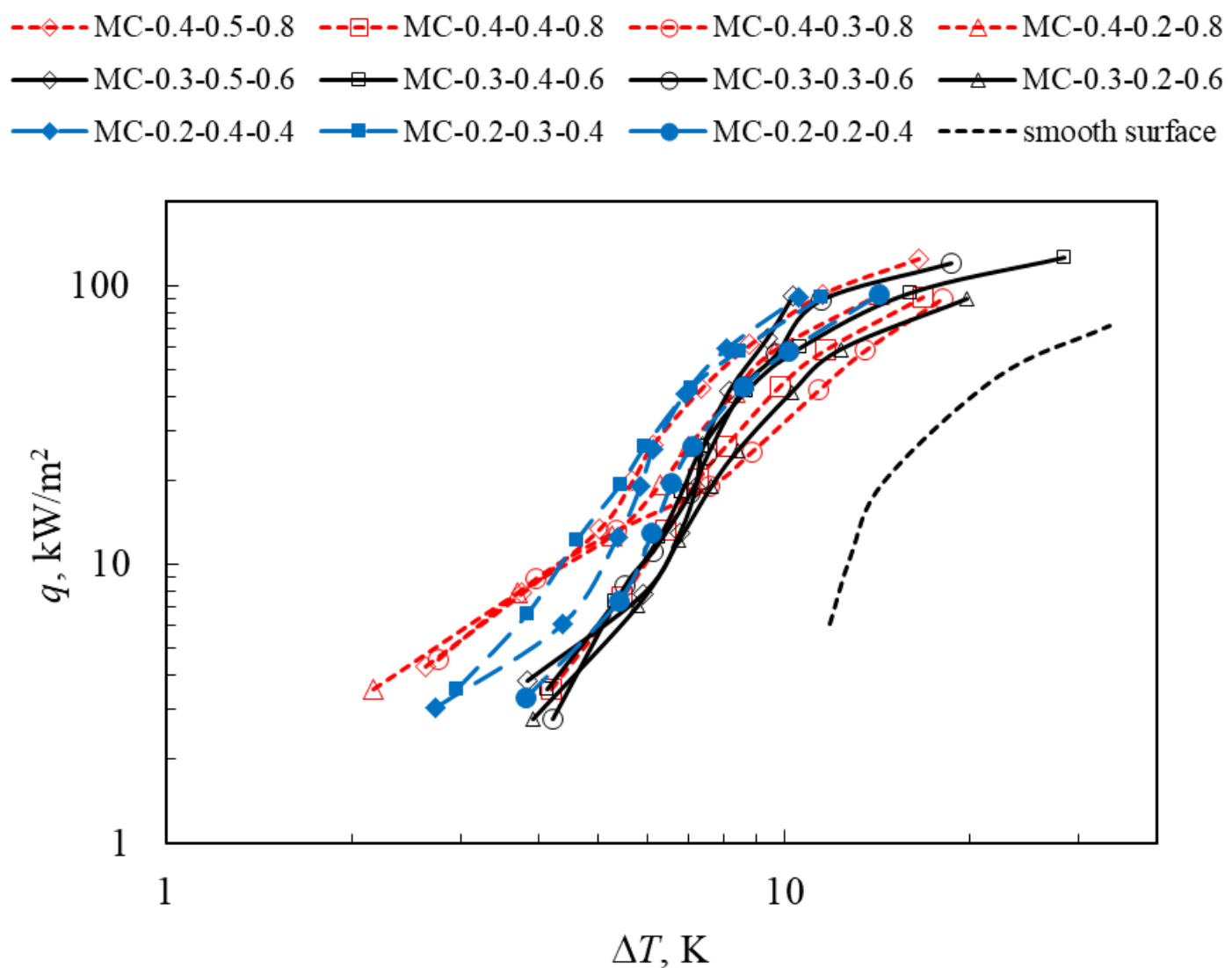

Fig. 6. Boiling curves for Novec-649, heat flux vs. temperature difference. 


\section{Nomenclature}

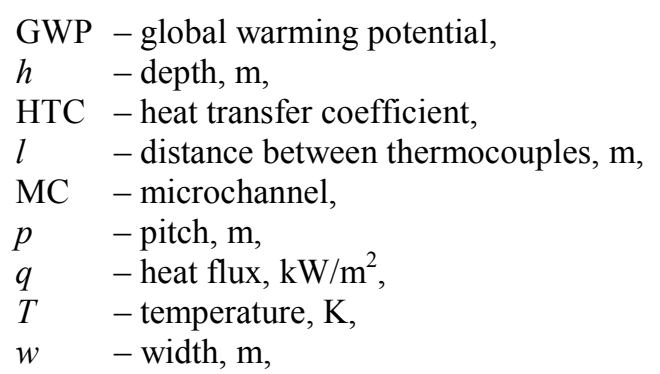

\section{Greek symbols}

$\alpha \quad-$ heat transfer coefficient, $\mathrm{W} /\left(\mathrm{m}^{2} \mathrm{~K}\right)$,

$\delta-$ thickness, mm,

$\lambda-$ thermal conductivity, $\mathrm{W} /(\mathrm{m} \cdot \mathrm{K})$,

$\Delta T$ - difference of temperature, $\mathrm{K}$,

\section{Subscripts}

$\begin{array}{ll}C u & - \text { copper, } \\ m & - \text { mean, } \\ S & - \text { sample, } \\ S n & - \text { tin. }\end{array}$

\section{References}

1. A. Jaikumar, S. Kandlikar, App. Therm. Eng. 91, 426-433 (2015).

2. A.M. Gheitaghy, A. Samimi, H. Saffari, App. Therm. Eng. 126, 892-902 (2017).

3. A. Walunj, A. Sathyabhama, App. Therm. Eng. 128, 672-683 (2018)

4. R. P. Sahu, S. Sinha-Ray, S. Sinha-Ray, A. L., Int. J. Heat \& Mass Transfer, 95, 83-93 (2016).

5. R. Kaniowski, R. Pastuszko, Ł. Nowakowski, EPJ Web of Conferences 143, 02049 (2017).

6. R. Kaniowski, R. Pastuszko, EPJ Web of Conferences 180, 02041 (2018).

7. R. Kaniowski, R. Pastuszko, EPJ Web of Conferences 180, 02042 (2018).

8. R. Pastuszko, Int. J. Therm. Sci., 125 197-209 (2018).

9. K. Strąk, M. Piasecka, B. Maciejewska, Int. J. Heat \& Mass Transfer, 117, 375-387 (2017).

10. B. Maciejewska, K. Strąk, M. Piasecka, Int. J. Num. Meth. for Heat \& Fluid Flow, 28, 1, 206-219 (2017).

11. M. Piasecka, K. Strąk, B. Maciejewska, Heat Transfer Eng., 38, 3, 332-346 (2016). 